\title{
Communication
}

\section{Jugulometer, a Medical Device: History, Description and Uses in Non-Invasive Assessment of Jugular Venous Pressure}

\author{
Oluwadare Ogunlade ${ }^{1, ~ *, ~ M u r i t a l a ~ A b i o l a ~ A s a f a ~}{ }^{1}$, Joseph Gbenga Omole ${ }^{1}$, Olusoji Adeola Adalumo ${ }^{2}$ \\ ${ }^{1}$ Department of Physiological Sciences, Obafemi Awolowo University, Ile-Ife, Nigeria \\ ${ }^{2}$ Department of Physiology, Federal University of Technology, Akure, Nigeria
}

Email address:

ogunladeomotomilayo@gmail.com (O. Ogunlade)

${ }^{*}$ Corresponding author

\section{To cite this article:}

Oluwadare Ogunlade, Muritala Abiola Asafa, Joseph Gbenga Omole, Olusoji Adeola Adalumo. Jugulometer, a Medical Device: History, Description and Uses in Non-Invasive Assessment of Jugular Venous Pressure. Cardiology and Cardiovascular Research.

Vol. 2, No. 1, 2018, pp. 4-7. doi: 10.11648/j.ccr.20180201.12

Received: December 26, 2017; Accepted: January 15, 2018; Published: February 1, 2018

\begin{abstract}
Jugular venous pressure (JVP) assessment is an important step in cardiovascular examination. JVP is an indirect measure of right atrial pressure / central venous pressure. The desire to measure JVP at bedside, though necessary during physical examination, is not easily achieved in most cases because of the difficulty in application of the two-ruler traditional method for its assessment. Jugulometer, a medical device designed and introduced at Ile-Ife in Nigeria for the purpose of non-invasive measurement of JVP at bedside. It is portable and easy-to-use. It consists of two bars (horizontal and vertical). The horizontal bar is embedded with spirit level while the vertical bar is graduated in centimetre. The two bars are assembled perpendicular to each other with a special mechanism which enable the vertical bar to slide over the horizontal bar without disrupting their perpendicular relationship. Jugulometer simplifies non-invasive measurement of JVP and makes the procedure more reproducible at bedside. This article is a documentation of the description, history of evolution of jugulometer and its uses in cardiovascular medicine and education. In conclusion, jugulometer is a medical device introduced at Ile-Ife in Nigeria to advance the traditional method and skill of non-invasive bedside assessment of jugular venous pressure.
\end{abstract}

Keywords: Jugulometer, Medical Device, Description, History, Uses, Jugular Venous Pressure

\section{Introduction}

Jugulometer is a medical device designed for non-invasive measurement of jugular venous pressure (JVP) at bed-side. JVP is an indirect, non-invasive measure of central venous pressure/right atrial pressure. Internal jugular vein is used for the procedure because of its easy visualization and the pressure changes within the vein reflects the phasic pressure changes within the right atrium. Non-invasive assessment of JVP is an important step in cardiovascular system examination The use of Doppler echocardiography to measure right atrial pressure has been reported but not readily available in developing countries [1-3]. Elevation of JVP is one of the most revealing clinical sign of congestive heart failure [4]. Measurement of JVP non-invasively is limited by logistics or procedural inefficiency limiting its reproducibility [5]. Jugulometer was introduced to improve the act of bed-side assessment of JVP.

\section{Description and Historical Background}

Jugulometer is designed for non-invasive measurement of JVP at bedside. It is portable, easy-to-use, more accurate than the traditional two-ruler method as it maintains perpendicularity of its components (horizontal and vertical bars) through a special assemblage mechanism upon positioning on the anterior chest wall. Moreover, the leverage of its horizontal bar is ensured through the use of microspirit level (Figure 1). 


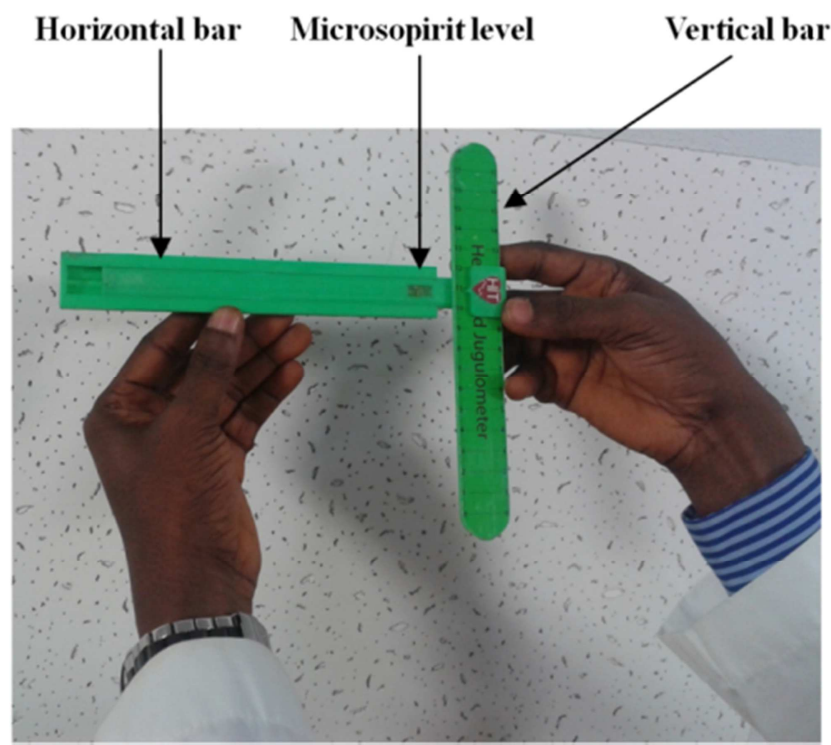

Figure 1. Description of Jugulometer, a medical device for non-invasive measurement of jugular venous pressure. Jugulometer is made up of vertical and horizontal components perpendicular to each other with a special assemblage mechanism.

\section{History of Jugulometer}

Jugulometer was invented in the year 2005 by a Nigerian Physician, Dr Oluwadare Ogunlade who was a resident doctor at the Obafemi Awolowo University Teaching Hospitals Complex (OAUTHC) Ile-Ife, Nigeria [6]. He described jugulometer as a device consisting of two bars knotted together and sliding across each other in a perpendicular manner. The horizontal bar was non-graduated but is maintained at an imaginary horizontal plane in which the lower border coincided with the top most portion of column of internal jugular venous pulsation while the vertical bar was graduated in centimetre. The lower end of the vertical bar was designed for positioning at the manubrosternal angle during bedside assessment of JVP [7]. The patent for jugulometer was obtained from the Federal Republic of Nigeria in 2005. Jugulometer was an improvement over the traditional two-ruler observational method of assessment of JVP described by Thomas Lewis in 1930 [8] and modified by Borst and Molhuysen in 1952 [9]. Various models of jugulometer are evolving with time. In 2015, Vincent et al described a model of jugulometer and called Zaria-made jugulometre [10]. In early 2016, the Heartmed model of the jugulometer was unveiled at Ile-Ife by Dr. O. Ogunlade, the inventor assisted by the collaborative inputs of Prof. M. O. Balogun, a renowned cardiologist at Obafemi Awolowo University Teaching Hospitals (OAUTHC) Ile-Ife, Prof. L. O. Adekoya and Mr. D. Adepoju, both of Department of Mechanical Engineering of Obafemi Awolowo University, Ile-Ife.

\section{Stages of Development}

There is advancement in the stages of development of jugulometer right from the time of its invention in 2005. It evolved from ordinary two bars with a knot joining the two. The vertical bar is fenestrated to allow it slide over the horizontal bar. However, the Heartmed model is an advancement on the initial models as it contained two special features for accuracy of the device. These include specialized inbuilt sliding mechanism at the point of intersection of vertical and horizontal components and presence of microspirit level embedded into the horizontal bar (Figures 2-5). Two types of materials had been used for its production; plastic and wood.

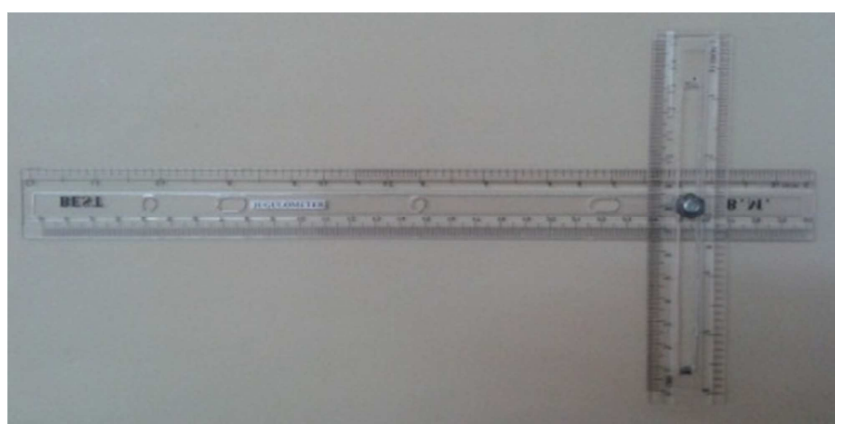

Figure 2. Jugulometer: Early Development (a plastic type).

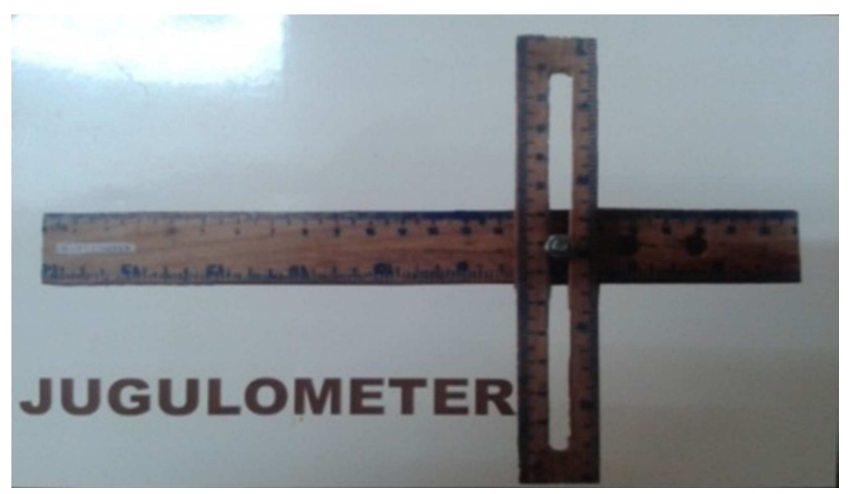

Figure 3. Jugulometer: Early Development (a wooden type).

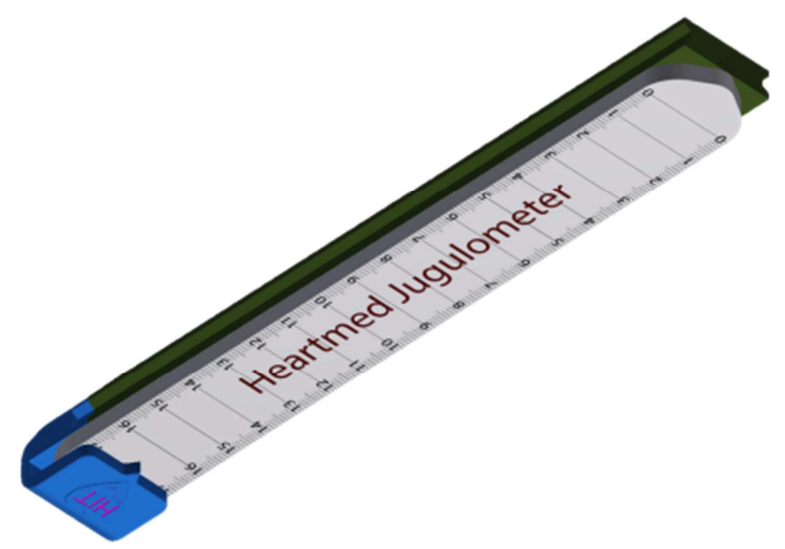

Figure 4. Heartmed Model of Jugulometer.

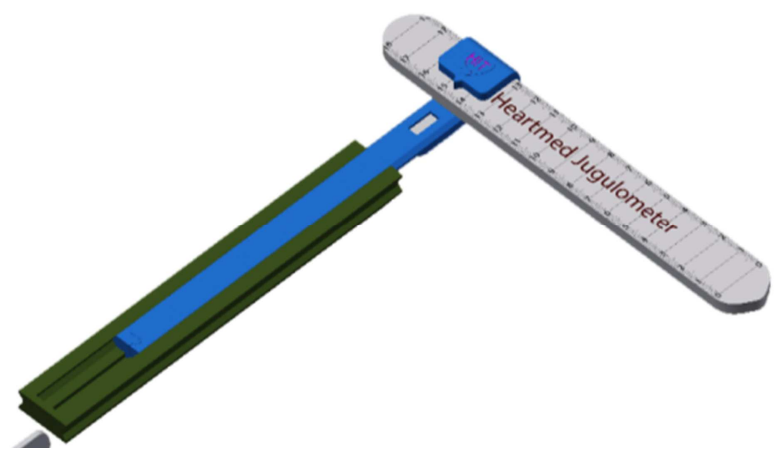

Figrue 5. Heartmed Model of Jugulometer. 


\section{Measurement of JVP Using Jugulometer}

In order to utilize jugulometer for non-invasive assessment of JVP at bedside, the following steps should be taken into consideration;

1. Expose the neck and upper thorax of the patient.

2. Position the patient at $45^{\circ}$ (cardiac position) to the horizontal with the head slightly elevated and sternocleidomastoid muscles relaxed (Figure 6).

3. Turn the head of the patient slightly towards the left side.

4. Under good illumination, examine the right anterior triangle of the neck.

5. Identify the mark or neck skin crease corresponding to the uppermost point of internal jugular venous pulsations.

6. Confirm that the pulsations observed are that of internal jugular vein and not that of carotid artery (Table 1).

Table 1. Differences between jugular venous and carotid pulsations.

\begin{tabular}{l} 
Jugular Venous Pulsation \\
\hline Rapid inward movement \\
Two peaks and troughs per heart beat \\
Upper level of pulsation changes with \\
phases of respiration (level descends with inspiration) \\
Upper level of pulsation changes with posture (level descends in upright \\
position but rises in incline position) \\
Rarely palpable (better seen than felt) \\
Pulsations eliminated by light pressure on the vessels at the root of the neck \\
Upper level of pulsation rises with firm pressure on the abdomen \\
(abdominojugular reflux)
\end{tabular}

7. The jugular venous pressure is measured as the vertical distance between the manubrosternal angle and the top of the pulsating internal jugular venous pulsations.

8. To measure JVP, place the lower pointed border of the vertical bar of jugulometer on the manubrosternal angle.

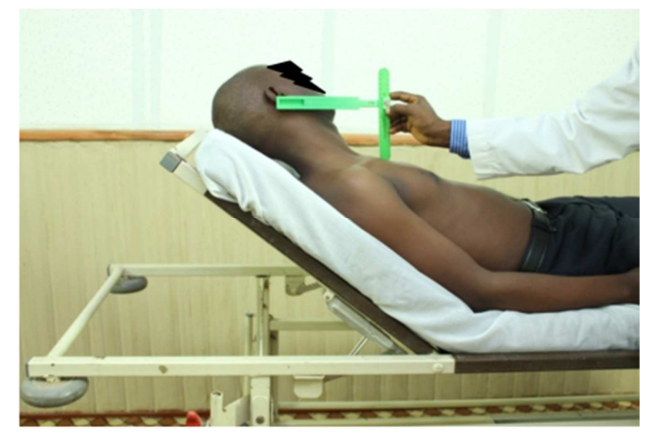

Figure 6. Positioning of client and jugulometer for measurement of JVP; An examiner demonstrating the use of jugulometer on a client positioned at angle $45^{\circ}$ on a couch. The lower end of jugulometer was placed on the manubrosternal angle while the horizontal bar was utilized to assess the most superior portion of jugular venous pulsation. The reading takes place on the vertical bar at the point of intersection of vertical and horizontal bars.

9. Adjust the horizontal bar by sliding it on the vertical bar in such a way that its lower border corresponds with the upper border of the internal jugular venous pulsating column.

10. To ensure that the horizontal bar is parallel to the horizontal plane, focus on the bubble within the microspirit tube and tilt the bar until the bubble is midpoint between the two marks of the microspirit tube (Figure 7).

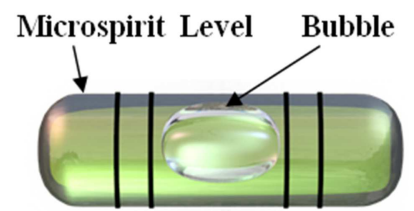

Figure 7. Bubble within the microspirit level.

\section{Carotid Pulsation}

Rapid outward movement

Single peak per heart beat

Upper level of pulsation unaffected by phases of respiration

Upper level of pulsation unaffected by postural change

Palpable (better felt than seen)

Pulsations not eliminated by light pressure on the vessels at the root of the neck

Upper level of pulsation unaffected by firm pressure on the abdomen
11. Read the vertical distance (in $\mathrm{cm}$ ) on the vertical bar using the pointer at the head of the horizontal bar.

12. The value $\mathrm{x} \mathrm{cm}$ obtained is the jugular venous pressure above the manubrosternal angle or $(x+5) \mathrm{cm}$ from the centre of the right atrium.

\section{Significance of JVP Measurement}

JVP is an important haemodynamic parameter which indirectly reflects the central venous pressure. It is a measure of the haemodynamic changes within the right atrium [11, 12]. The normal range of value of JVP in an adult is $6-8 \mathrm{~cm} \mathrm{H}_{2} \mathrm{O}$ above the manubrosternal angle. In a healthy individual, jugular venous pulsation is not visible because it is in a collapsed state upon sitting erect and may barely be visible at the root of the neck when the person is inclined at $45^{\circ}$. When there is cardiovascular disorder associated with elevated venous filling pressure, jugular venous pulsations are visible and the topmost point (level) of the pulsation can be observed and measured. A JVP value $<5 \mathrm{~cm}$ $\mathrm{H}_{2} \mathrm{O}$ above manubrosternal angle is low and may reflect hypovolaemia while a value $\geq 9 \mathrm{cmH}_{2} \mathrm{O}$ is elevated and reflects elevated venous filling pressure. The usefulness of JVP assessment at bedside cannot be overemphasized although the procedure is largely omitted during routine cardiac examination due to non-availability of appropriate tool for the measurement. Hence, assessment of the JVP is often inadequately performed and undervalued in clinical practice [12]. Elevated JVP is one of the diagnostic criteria for congestive heart failure [13-15]. Measurement of JVP is therefore central to the diagnosis of congestive heart failure. Serial monitoring of JVP in patients with heart failure is also essential for assessment of effectiveness of therapy and prognosis [16]. Elevation of JVP may be due to the following clinical conditions;

1. Congestive heart failure

2. Right heart failure

3. Fluid overload

4. Right ventricular infarction

5. Cor pulmonale 
6. Constrictive pericarditis

7. Pericardial effusion

8. Cardiac tamponade

9. Tricuspid regurgitation

10. Atrioventricular dissociation;

a. Complete heart block

b. Ventricular tachycardia

c. Idioventricular rhythm

d. Junctional rhythm

11. Pacemaker syndrome

12. Restrictive cardiomyopathy

13. Superior vena caval obstruction

\section{Conclusion}

Jugulometer is a medical device introduced at Ile-Ife in Nigeria to advance the traditional method and skill of non-invasive bedside assessment of jugular venous pressure.

\section{Acknowledgements}

Appreciation to collaborating colleagues and professors in the Departments of Medicine and Mechanical Engineering, Obafemi Awolowo University, Ile-Ife. The contributions of the Audiovisual Unit of College of Health Sciences and the Technical Staff of the Department of Physiological Sciences, Obafemi Awolowo University, Ile-Ife who were involved in capturing the images of the models are appreciated.

\section{References}

[1] Nagueh, S. F., Kopelen, H. A., Zoghbi, W. A (1996). Relation of mean right atrial pressure to echocardiographic and Doppler parameters of right atrial and right ventricular function. Circulation, 93, 1160-9.

[2] Ommen, S. R., Nishimura, R. A., Hurrell, D. G., Klarich, K. W (2000). Assessment of right atrial pressure with 2-dimensional and Doppler echocardiography: a simultaneous catheterization and echocardiography study, Mayo Clin Proc, 75, 24-9.

[3] Brennan, J. M., Blair, J. E., Goonewardena, S., Ronan. A., Shad, D., Vasslwala, S., et al.(2007). Reappraisal of the use of inferior vena cava for estimating right atrial pressure, $J \mathrm{Am}$ Soc Echocardiogr, 20,857-61.
[4] Fonseca, C., Morais, H., Mota, T., Matias, F., Costa, C., Gouviea-Oliveira, A., Ceia, F. (2004). "The diagnosis of heart failure in primary care: value of symptoms and signs". Eur $J$ Heart Fail, 6 (6), 795-800.

[5] Stevenson, L, W., Perloff, J. K. (1989). "The limited reliability of the physical signs for estimating haemodynamic in chronic heart failure". JAMA, 261, 884-8.

[6] Ogunlade, O. (2005). Oodua Handbook of Jugular Venous Pressure. AndKolad Publishers Limited, Ile-Ife.

[7] Ogunlade, O., Akintomide, A. O., Adebayo, R. A., Ogunlade, B (2008). Jugulometer: An adaptation for measurement of jugular venous pressure. Nigerian Journal of Postgraduate Medicine, 2, 41-44.

[8] Lewis, T (1930). Remarks on early signs of cardiac failure of the congestive type. $\mathrm{Br}$ Med $J, 1,849-852$.

[9] Borst, J. G. G., Molhuysen, J. A (1952). "Exact determination of the central venous pressure by a simple clinical method". The Lancet, 260 (6729), 304-309.

[10] Vincent, S. Y., Nathaniel, G. G., Peter, Y. D., Solomon, S. S (2015). "Zaria-made jugulometre: Assessing its usefulness in bedside medicine". Nigerian Journal of Cardiology, 12 (2), 77-80.

[11] Constant J (2000). Using internal jugular pulsations as a manometer for right atrial pressure measurements. Cardiology, 93, 26-30.

[12] Naveen, G., Nitish, G (2000). Jugular venous pulse: an appraisal. Journal, Indian Academy of Clinical Medicine, 1, 260-269.

[13] Chua Chiaco, J. M. S., Parikh, N. I., Fergusson, D. J (2013). The jugular venous pressure revisited, Cleve Clin J Med. 80, 638-644.

[14] Dosh, S. A (2004). Diagnosis of heart failure in adults. Am Fam Physician, 70, 2145-2152.

[15] King, M., Kingery, J., Casey, B (2012). Diagnosis and evaluation of heart failure, Am Fam Physician, 85, 1161-8.

[16] Drazner, M., Rame, J., Stevenson, L., Dries, D. L (2001). Prognostic importance of elevated jugular venous pressure and a third heart sound in patients with heart failure. $N$ Engl $J$ Med, $23,345,574-81$. 